\title{
Perbandingan Tingkat Penyembuhan Tulang Antara Isolated Tibial Diaphyseal Fracture, Both Tibial dan Fibula Diaphyseal Fracture Setelah Terapi Interlocking Intramedullary Solid Nail
}

\author{
${ }^{1}$ Muhammad Rustam HN, ${ }^{1}$ Nina Indriyani \\ ${ }^{1}$ Fakultas Kedokteran Universitas Halu Oleo \\ Email : rustam.noertika@gmail.com
}

\begin{abstract}
One of the fixation method is interlocking intramedullary solid nail that can enhance the callus formation in tibial diaphyseal fracture through the secondary healing. The research aimed to compare the rate of bone healing between isolated tibial diaphyseal fracture and both diaphyseal tibial and fibular fracture after therapy solid interlocking intramedullary nail. This research was conducted by comparing the results of the cure rate among patients with isolated fractures of the tibia and fracture of the tibia with fractures of the fibula during November 2007 to December 2015. The first group, comprising 29 patients and the second group comprised 47 patients. All patients had solid action intramedullary nail. The evaluation was done 30 weeks post-surgery, to assess the Union Rate using Radiographic Union Score for tibial Fractures (RUST). Data were analyzed using non-parametric test of Mann-Whitney test for comparing the union rate between the two groups. The results showed that 27 of 29 patients with isolated tibial fractures had RUST score $\geq 7$ and 2 patients with RUST score $<$ 7. Meanwhile, 44 patients out of 47 patients with both diaphyseal tibial and fibular fracture, having RUST score $\geq 7$ and 3 patients with a score $<7$.

Keywords: Interlocking intramedullary solid nail, Isolated Tibial Diaphyseal Fracture Radiographic Union Score, Unionrate
\end{abstract}

\section{PENDAHULUAN}

Tulang terdiri dari sel-sel, matriks protein dan endapan mineral (Einhom dkk., 2015). Tiga sel dasar adalah osteoblas, osteosit, dan osteoklas. Osteoblas berkontribusi dalam pembentukan tulang dengan mensekresikan matriks tulang.

Osteosit terlibat dalam pemeliharaan fungsi tulang dan terletak di dalam osteon, sementara osteoklas adalah sel multinuklear mengambil bagian dalam penghancuran, resorpsi dan remodeling tulang (Shapiro, 2015).

$$
\text { Fraktur adalah hilangnya }
$$

kontinuitas jaringan tulang, baik jaringan tulang atau tulang rawan (Einhom dkk., 2015). Itu terjadi ketika energi yang ditransmisikan ke tulang lebih besar daripada pembatasan kekuatan tulang (Shapiro, 2015).

Tibia adalah salah satu tulang terbesar di tubuh kita, terletak anteromedial di ekstremitas bawah (Museru dkk., 2002). Tibia berkontribusi untuk berat tubuh, diartikulasikan dengan kondilus femur proksimal dan talus distal (Muller dkk., 1990). Segmen diaphyseal terletak antara segmen proksimal dan distal (Lawrence dan Bone,1997).

Penyebab utama fraktur tibial adalah kecelakaan kendaraan bermotor, cedera olahraga dan trauma langsung ke tibia (Museru dkk., 2002). Dampak energi yang lebih tinggi akan menghasilkan fraktur tibia-fibula, sementara dampak energi yang lebih rendah akan menghasilkan fraktur tibialis terisolasi (Shapiro, 2015).

Klasifikasi fraktur diaphyseal tibia sesuai dengan klasifikasi AO/ ASIF yang dibagi menjadi sembilan kelompok sesuai dengan kompleksitas morfologi dan kesulitan perawatan serta prognosis (Museru dkk., 2002). 

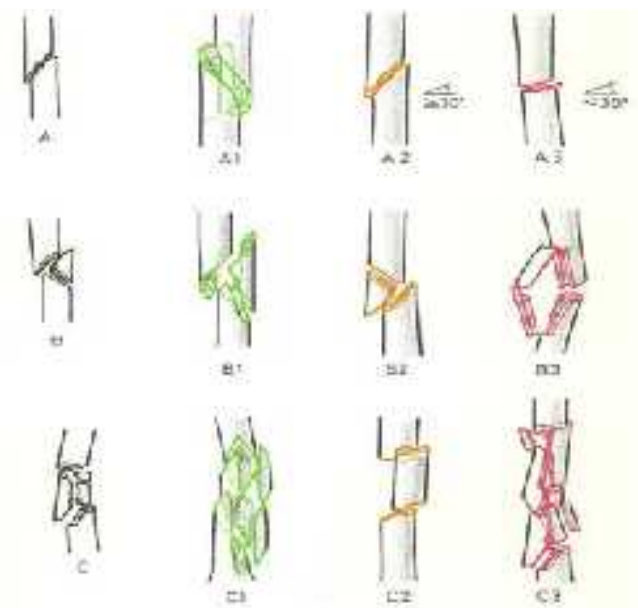

Gambar 1. Klasifikasi AO / ASIF untuk Fraktur Diaphyseal

Gambar 1 menunjukkan bahwa Penanganan awal untuk fraktur tibia adalah splint posterior yang panjang dengan lutut tertekuk 10-15 ${ }^{\circ}$ dan pergelangan kaki tertekuk $90{ }^{\circ}$, diikuti oleh prinsip R.I.C.E. Metode perawatan non-operasi termasuk reduksi tertutup dan imobilisasi menggunakan cast (penyangga fungsional). Metode ini digunakan dalam kasus fraktur tertutup.

Banyak pilihan untuk metode operasi pada kasus ini, termasuk intramedullary nail, flexible nail (Enders, Rush rods), external fixation and plate \& screw (Einhom dkk, 2015).

Komplikasi termasuk malunion, persalinan tertunda, non union, kekakuan sendi lutut dan sendi pergelangan kaki yang terinfeksi, nyeri lutut, kegagalan implan dan sindrom kompartemen (Einhom dkk., 2015)

Prinsip IM Nailing adalah pembagian beban dan perisai stres minimal (Zelle, 2015). Beban berat progresif pada sisi fraktur kallus akan meningkatkan penyembuhan fraktur dan remodeling (Omerovic dkk., 2010).
RUST (Radiographic Union Scale for Tibial Fracure) adalah metode untuk menentukan penyembuhan tulang dengan mengamati pembentukan kalus dan garis fraktur di empat korteks, korteks anterior, posterior, lateral dan medial. Skor minimum adalah 4 dan skor maksimal adalah 12 (Ali, 2014).

Semakin tinggi skor RUST berarti semakin banyak pertumbuhan kalus dan berkurangnya garis fraktur, berarti proses penyembuhan tulang akan terjadi (Ali, 2014). Pengukuran Skor RUST dapat dinilai dengan menggunakan radiografi standar menggunakan AP dan proyeksi lateral (Ali, 2014).

\section{METODE}

Penelitian ini merupakan penelitian kohort retrospektif yang dilakukan di RSUP Dr. Wahidin Sudirohusodo, Makassar dari Desember 2015 hingga Maret 2016 dengan total sampel 71 pasien yang menjalani operasi dengan Interlocking Intermedullary Solid Nail dengan menilai X-Ray kontrol pasien tersebut yang secra kontinyu melalui 5 periodik minggu $(6,12,18,24$, dan 30 minggu)

Subyek penelitian ini harus memenuhi kriteria inklusi dan eksklusi. Kriteria inklusi adalah Pasien Isolated Tibial Diaphyseal Fracture dan both diaphyseal tibial and fibula fracture yang telah dilakukan prosedur operasi pelepasan sekrup Interlocking intramedullary solid nail di RSUP Dr. Wahidin Sudirohusodo, Makassar dalam periode waktu November 2007 sampai dengan Desember 2015, Laki-laki atau perempuan dengan usia 16 tahun keatas, Type fraktur transversal, obliq dan segmental, Pasien dalam keadaan sehat dan telah dilakukan follow 
up minimal 3 bulan pasca tindakan operasi. Kriteria eksklusi adalah Pasien Isolated Tibial Diaphyseal Fracture dan both diaphyseal tibial and fibula fracture yang telah dilakukan prosedur operasi pelepasan sekrup Interlocking intramedullary solid nail di RSUP Dr. Wahidin Sudirohusodo pasien dengan defisit neurologis, fraktur patologis, trauma multipel, fraktur tibia kominutif yang bukan indikasi IM Nailing.

\section{HASIL}

Dari jumlah pasien yang diteliti adalah 71 orang memenuhi kriteria inklusi. Usia subjek antara 16-68 tahun. Analisis lengkap hasil dijelaskan dengan mengikuti.
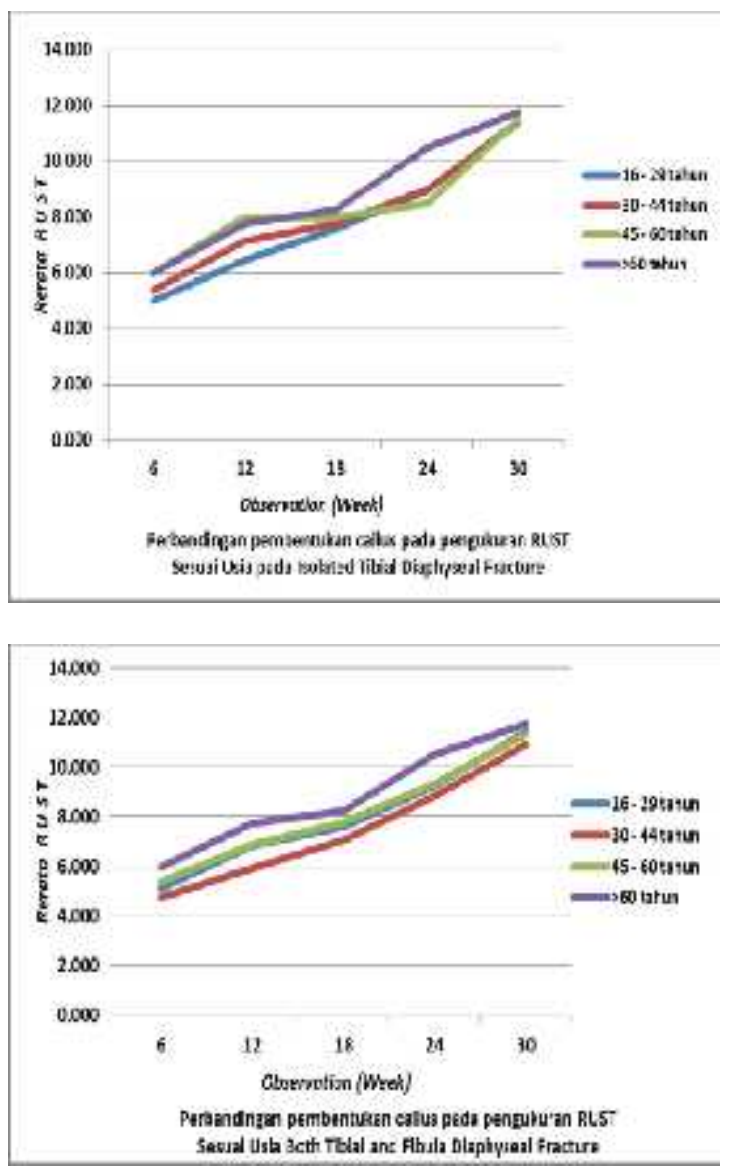

Gambar 2. Distribusi Usia Subjek dari

Isolated Tibia / Fraktur Tibia-Fibula
Gambar 2 menunjukkan distribusi usia subjek di kedua kelompok fraktur tibialis terisolasi dan kedua kelompok fraktur tibia-fibula. Usia rata-rata adalah 32,2 tahun.
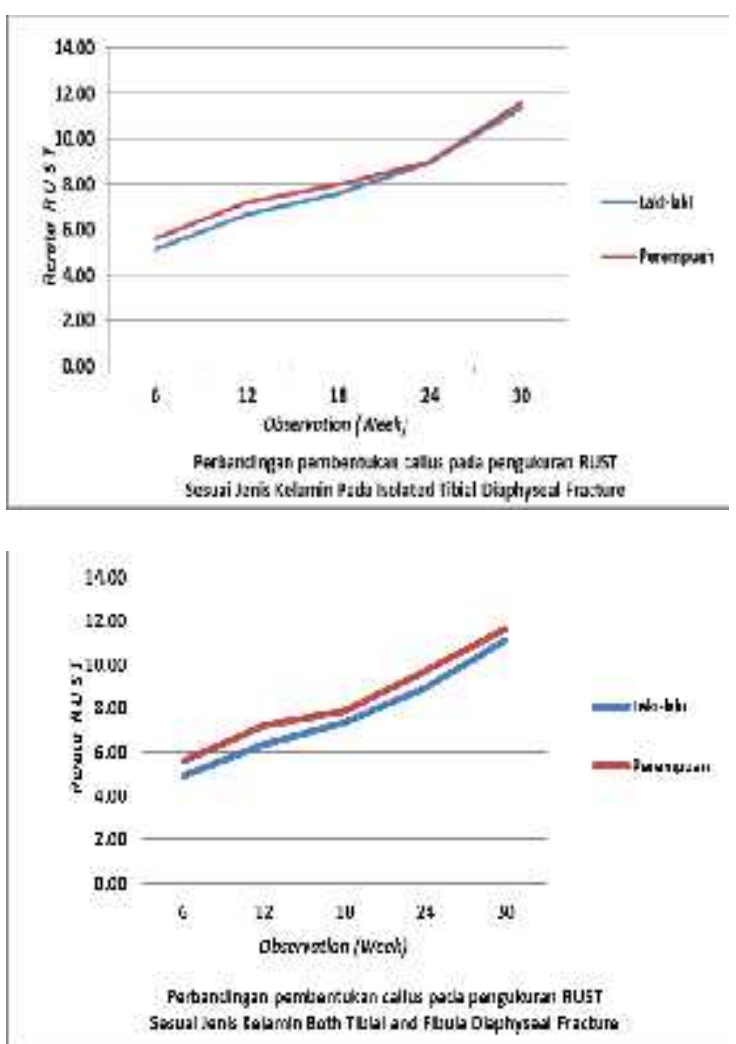

Gambar 3. Distribusi subjek seks dari Isolated Tibia / Fraktur Tibia-Fibula

Gambar 3 di atas menunjukkan bahwa subyek laki-laki lebih dari perempuan dalam kelompok tbial-fibula, 28 laki-laki $(62,2 \%)$ dan 16 perempuan (37,8\%). Dalam kelompok tibialis terisolasi, 22 pasien $(81,5 \%)$ adalah lakilaki dan 5 pasien $(18,5 \%)$ adalah perempuan. 

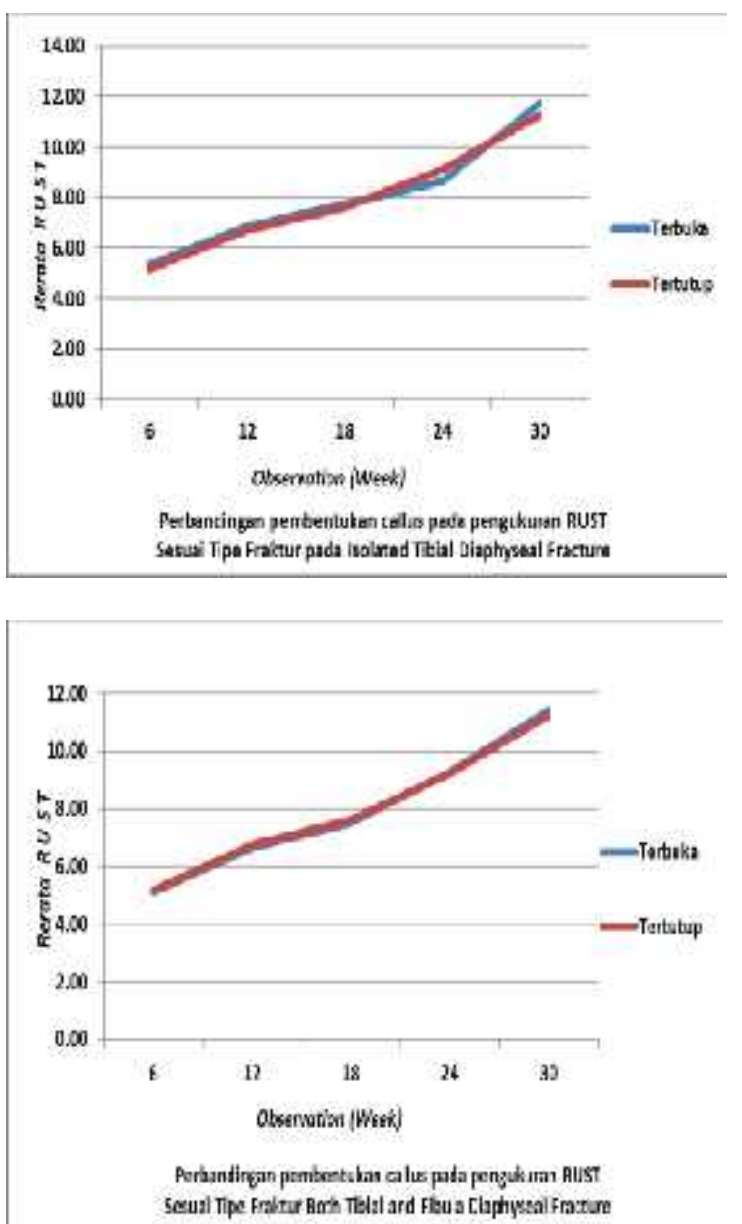

Gambar 4. Distribusi Jenis Fraktur dari Isolated Tibia / Kedua Fraktur TibiaFibula

Gambar 4 menunjukkan kasus fraktur terbuka vs tertutup pada fraktur tibia-fibula adalah keseimbangan (51,1\% vs 48,9\%) sedangkan fraktur tertutup lebih terbuka daripada terbuka pada fraktur tibialis terisolasi $(70,4 \%$ vs $29,6 \%)$.

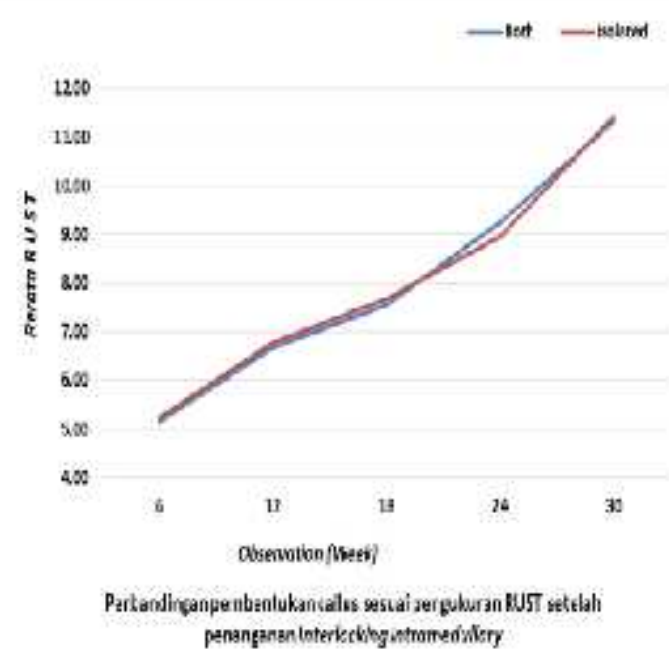

Gambar 5. Formasi kalus oleh pengukuran RUST pada kedua kelompok

Gambar 5 menunjukkan garis kalus yang hampir seimbang pada kedua kelompok.

Tabel 1. Analisis statistik RUST pada kedua kelompok berdasarkan interval pengamatan

\begin{tabular}{|c|c|c|c|c|c|c|c|}
\hline \multirow{6}{*}{$\begin{array}{l}\text { Fis : } \\
\text { Minyal }\end{array}$} & & \multirow[b]{4}{*}{ H } & \multirow[b]{4}{*}{ "Eten } & \multicolumn{4}{|c|}{ 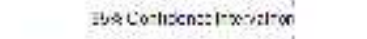 } \\
\hline & i & & & \multirow{2}{*}{$=x$} & \multirow{2}{*}{\multicolumn{2}{|c|}{ keall }} & \multirow{6}{*}{0.312} \\
\hline & 1 & & & & & & \\
\hline & ! & & & 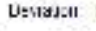 & \multicolumn{2}{|c|}{ 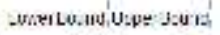 } & \\
\hline & Fot: & -4 & in 77 & sar & $\mathrm{fi}<\mathrm{n}_{\mathrm{i}}^{\prime}$ & 7.81 & \\
\hline & Lan mast & $2 n_{1}^{\prime}$ & 657 & sis & $k x x_{1}^{\prime}$ & $8 \pi_{1}^{1}$ & \\
\hline & $\operatorname{Tr} a$ & -11 & Кำ & $m s$ & $\kappa ; \lambda_{1}^{\prime}$ & $=x_{1}^{\prime}$ & \\
\hline nus : : & EA: & 4 & $6 \mathrm{be}$ & $\mathrm{CT}:$ & $12=1$ & issi & vis \\
\hline \multirow[t]{2}{*}{ Ni=y:-6? } & 130305 & $2 \pi$ & 77 & 运 & 752 & 7.55 & \\
\hline & 1000 & ;1 & $i v i$ & ise &  & issel & \\
\hline ris:-: & $r * t$ & 2 & $9-\pi$ & S2:F & $n+21$ & $8: 5$ & กא: \\
\hline \multirow[t]{2}{*}{ Nilme: } & 1500005 & $2 i$ & yoi & is & sid & S.3. & \\
\hline & Tora & 71 & $8=1$ & $20 \mathrm{BC}$ & 008 & 5.92 & \\
\hline rus: 21 & c.t & 11 & $1 \% 2$ & one & $1.2 \%$ & 4.71 & 095 \\
\hline \multirow[t]{2}{*}{ 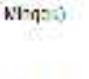 } & Isuaded & $2 i$ & $1 \% 2$ & $\Leftrightarrow=$ & woyyl & 1.5: & \\
\hline & Ius & 11 & $1-1$ & 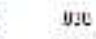 & $1+2:$ & 1.51 & \\
\hline \multirow{4}{*}{ 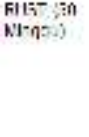 } & For & (1) & $1 \leqslant 31$ & 87. & $12 n$ & $17 ?$ & $n, m, 3$ \\
\hline & 'buase: & $n$ & $v:=1$ & $\because$ & woss & $1.5 s$ & \\
\hline & $1 \mathrm{~mm}$ & $i 1$ & $12 x_{t}$ & xes & $133\}_{1}^{\prime}$ & $1+\mathrm{it}_{1}^{\prime}$ & \\
\hline & $i$ & : & & & ! & ! & \\
\hline
\end{tabular}

Tabel 1 Menunjukkan Analisis statistik menggunakan T-test independen selama 6, 12, 18, 24 minggu mengungkapkan tidak ada perbedaan yang 
signifikan untuk penilaian RUST pada kedua kelompok $(\mathrm{p}>0,05)$.

Tabel 2. Analisis statistik RUST pada kedua kelompok menurut umur

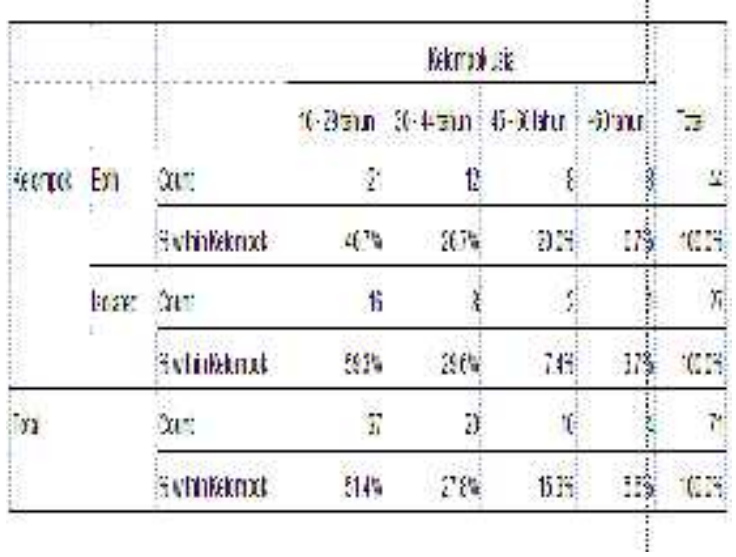

Tabel 2 Menunjukkan Analisis statistik menggunakan T-test independen untuk usia 16-29 tahun, 30-44 tahun, berusia 45-60 tahun, dan $>60$ tahun tidak menunjukkan perbedaan signifikan untuk penilaian RUST di semua kelompok ( $\mathrm{p}>$ $0,05)$.

Tabel 3. Analisis statistik RUST pada kedua kelompok berdasarkan tipe fraktur

\begin{tabular}{|c|c|c|c|c|c|}
\hline & & & \multicolumn{2}{|c|}{ Tise rads } & \multirow[b]{2}{*}{-ctal } \\
\hline & & & Fouce & Inubp & \\
\hline \multirow[t]{4}{*}{ Selompor: } & $=\mathrm{cllh}$ & Carl & 2 & 2 & $\angle$ \\
\hline & & 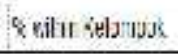 & $51 \%$ & 48.93 & $100.3 \%$ \\
\hline & so sted & Carl & $\varepsilon$ & 9 & 27 \\
\hline & & \& vihr selomoxe & $2 \leqslant 6 \%$ & 70.23 & $100.3 \%$ \\
\hline \multirow[t]{2}{*}{$|x|$} & & carl & 31 & 41: & $\pi$ \\
\hline & & \& wihr selaרos & 43.4 & 56.33 & $00.3 \%$ \\
\hline
\end{tabular}

Tabel 3 menunjukkan tidak ada hasil yang signifikan antara tipe fraktur dari kedua kelompok terhadap penilaian RUST ( $p>0,05)$.

\section{PEMBAHASAN}

Sandra dkk.(2005) menyatakan bahwa fibula utuh tidak lebih memberikan prognosis buruk untuk penyembuhan tulang, bersama dengan Leach (1984) karena adanya penghentian torsi tibial.

Nonunion dan delayed union dalam fraktur diaphysis tibia adalah salah satu komplikasi dalam metode intramedullary solid nailing yang saling mengikat (Yang dkk., 2013). tanpa menghiraukan fibula utuh atau tidak.

Kondisi dinamis akan menyebabkan reduksi yang kurang dan pemendekan pada fraktur kominutif, sehingga diperlukan operasi kedua. Tetapi keuntungan utama dari kondisi dinamis adalah mempercepat union pada kasus delayed union (Zirkle,2007).

Penelitian ini mengungkapkan bahwa proses penyembuhan fraktur diaphyseal tibia memakan waktu sekitar 24 minggu. Tidak ada perbedaan yang signifikan dalam pembentukan kalus antara fraktur tibia yang terisolasi dengan fraktur tibia fibula.

Dalam penelitian ini, tingkat persatuan sangat baik dalam 95\% kasus sehingga membuat intramedullar solid nailing menjadi pilihan pengobatan yang dapat diandalkan.

Fraktur femur proksimal biasanya terlihat pada pasien lansia sehingga meningkatkan masalah medis dan sosial ekonomi. Keterbatasan mobilitas pascafraktur adalah masalah yang sering dan diperparah oleh penurunan kekuatan otot tungkai bawah.

\section{SIMPULAN}

Tidak ada perbedaan yang signifikan dalam tingkat persatuan antara fraktur diaphyseal terisolasi tibia dan 
fraktur diaphyseal tibia fibula. Fibula utuh yang tidak mempengaruhi penyembuhan tulang tidak perlu dilakukan tindakan osteotomi pada kasus fraktur tibialis yang terisolasi.

\section{SARAN}

Saran yang bisa kami tawarkan adalah sebaiknya untuk penelitian seperti ini lebih banyak di lakukan untuk lebih menambah wawasan ilmiah khususnya dibidang orthopedi. Selain itu, untuk penelitian selanjutnya bisa disempurnakan lagi dengan analisa yang lebih kompleks.

\section{DAFTAR PUSTAKA}

Ali, S. 2014. Reliability of the RUST Score for the Assessment of Union in Simple Diaphyseal Tibial Fractures. 05: 05.

Einhorn, T.A., and Louis, C. 2015. Fracture healing: mechanisms and interventions, 11(1): 45-54.

Lawrence, B., dan Bone, M.D. 1997. Displaced Isolated Fractures of the Tibial Shaft Treated with Either a Cast or Intramedullary Nailing An outcome analysis of matched pairs of patients. The Journal of Bone and Joint Surgery.

Museru, L.M., McHaro, C.N. 2002. The dilemma of fracture treatment in developing countries. Int Orthop. 26(6):324-7.

Omerovic, D., Lazovic, F. 2010 Static or Dynamic Intramedullary Nailing of Femur and Tibia. $J$ Orthop Trauma. 24:S81-S86.

Sandra, J.S., Augat, P., Claes, L., Alexander. 2005. Intact fibula improves fracture healing in a rat tibia osteotomy model. Journal of Orthopaedic Research.

Shapiro, F. 2015. Bone development and its relation to fracture repair. The role Of mesenchymal osteoblasts and surface osteoblasts. Orthopaedic Research Laboratories, Children's Hospital Boston, Boston MA. 15: 53 - 76.

Yang, J.S., Otero, J.M.D., Christopher, M., McAndrew, M,D., William, M., Ricci, M.D., Garner, M.J. 2013. Can tibial nonunion be predicted at 3 months after intramedullary nailing?. J Orthop Trauma. 27(11): 599-603.

Zirkle, Jr, L.G. 2007. Technique Manual of SIGN IM Nail \& Interlocking Screw System Insertion \& Extraction Guide.

Zelle, B,A. 2015. Safe surgical technique: intramedullary nail fixation of tibial shaft fractures. Patient Safety in Surgery. 9:40. 